\title{
Variations of the Extrahepatic Biliary Tract: Cadaveric Study.
}

\author{
*Dr.Satarupa Paul, **Dr.J. Sujitha Jacinth, ***Dr.V. Muniappan. \\ *Postgraduate student, **Lecturer, ${ }^{* * *}$ Professor \& HOD, Division of Anatomy, Rajah Muthiah Medical \\ College, Annamalai University, Chidambaram, Tamilnadu, India - 608002.
}

\begin{abstract}
The extra-hepatic biliary tract includes: right and left hepatic ducts, common hepatic duct, gallbladder, cystic duct and common bile duct. The variation in this system is seen in less than $50 \%$ of the cases. This study was carried out to describe the anatomical variations of the extra-hepatic biliary tract as these variations are important during surgical procedures such as laparoscopic cholecystectomy thereby decreasing the post-operative complications.
\end{abstract}

Key words: Extrahepatic biliary tract, cystic duct, laparoscopic cholecystectomy.

\section{Introduction:}

Extra-hepatic biliary tract collects the bile from the liver and drains it into the second part of the duodenum. It is known for its variations. The common variations are intrahepatic union of right and left hepatic ducts, accessory hepatic ducts, different mode of termination of common hepatic duct, cystic duct and common bile duct. The variations in this study are intrahepatic union of right and left hepatic ducts, termination of the cystic duct on the left side of the common bile duct and accessory hepatic ducts. In normal individual anomalies in this region does not create any medical emergencies but it may produce significant complications following the surgeries pertain to this region.

\section{Materials and Method:}

The study was carried out in 50 adult specimens of liver, gallbladder with duodenum from the well embalmed cadavers, for a period from August 2011 - July 2013 in the department of Anatomy, Rajah Muthiah Medical College, Chidambaram, India. Collection of specimen: Unclaimed and donated bodies were officially received in the Department of Anatomy. The bodies were first embalmed in the department for the purpose of dissection. Later at a convenient time, the extra-hepatic biliary trees were dissected.

\section{Dissection and Processing:}

The anterior abdominal wall was incised from xiphoid process to pubic symphysis and opened layer by layer. Peritoneum was opened and the viscera were carefully separated and cleaned from the field of view. Each of the extra-hepatic biliary apparatus was traced proximally and distally [1], and photographs were taken. Relevant data were recorded and compared with that of other authors.

\section{Observation and Results:}

In the present study 50 cadavers were examined for the anatomical pattern and the variation of the extra-hepatic biliary tract.

Case 1: Usually main right (short and vertical course) and left (horizontal course) hepatic ducts emerge from the liver and unite near the right end of the porta hepatis as the common hepatic duct. In the present study, in 2 out of 50 specimens the right and left hepatic ducts united intrahepatically [Figure 1].

Case 2: Normally the cystic duct drains on the right side of the common hepatic duct, but in 1 specimen it drains on the left side [Figure 2].

Case 3: In the present study accessory hepatic duct was found in 3 specimens. In all these specimens the accessory hepatic duct arose from the inferior surface of the right lobe of the liver and drained into neck of the gallbladder [Figure 3].

Schematic presentation of these variations: 


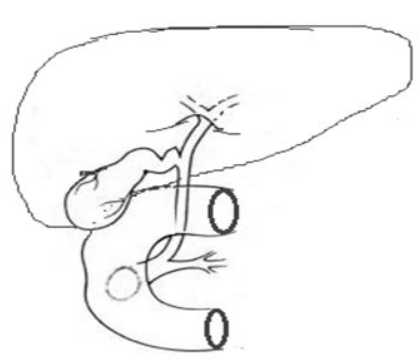

Case 1

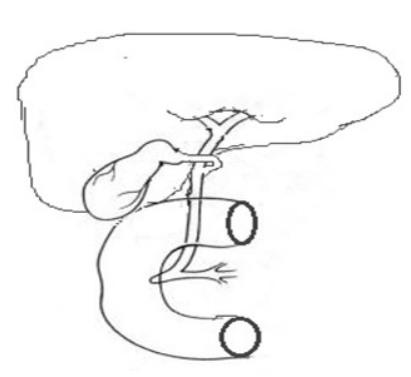

Case 2

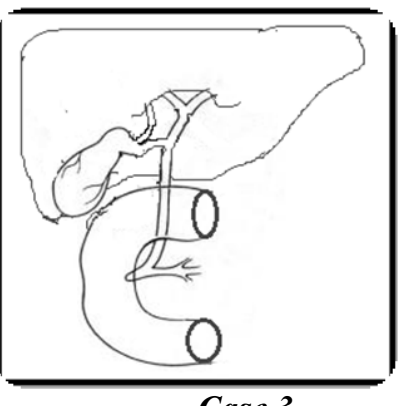

Case 3

Figure 1: Intrahepatic union of the right and left hepatic ducts.

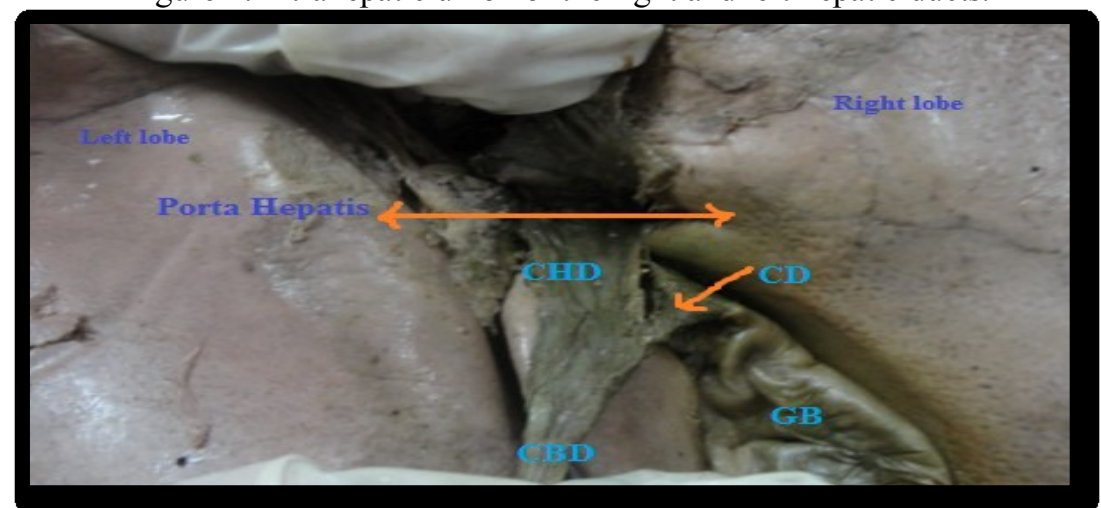

Figure 2: Cystic duct draining on the left side of common hepatic duct

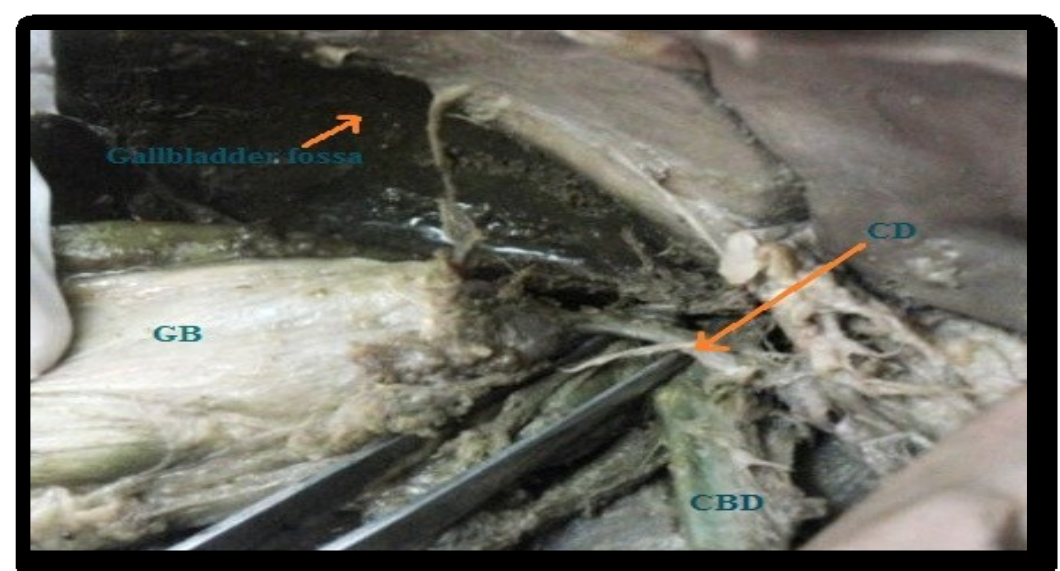

Figure 3: Accessory hepatic duct.

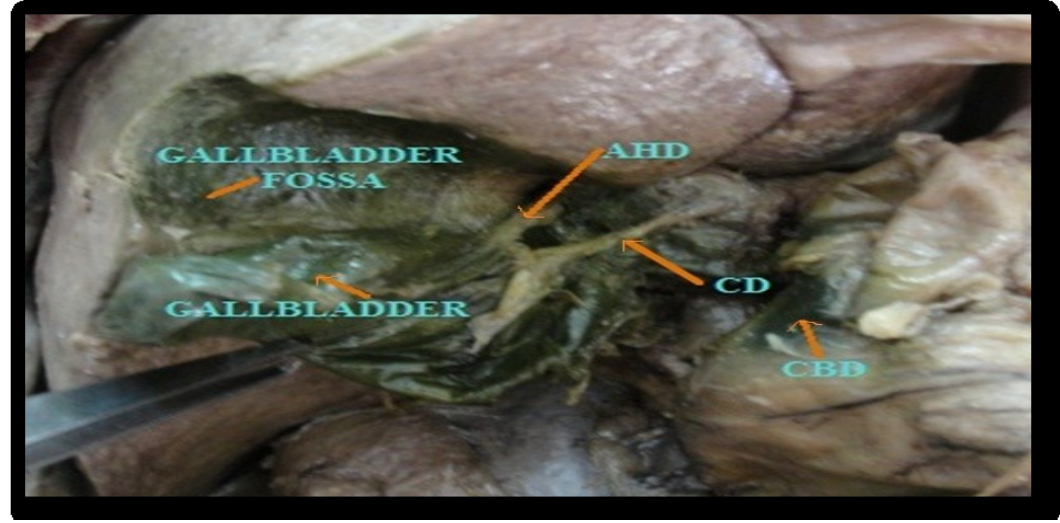

Abbreviations:

$\mathbf{C H D}=$ Common hepatic duct $\mathbf{C D}=$ Cystic duct; $\mathbf{G B}=$ Gallbladder; $\mathbf{C B D}=$ Common bile duct; $\mathrm{ACD}=$ Accessory hepatic duct. 
Figure 4: Incidence of the formation of common hepatic duct.

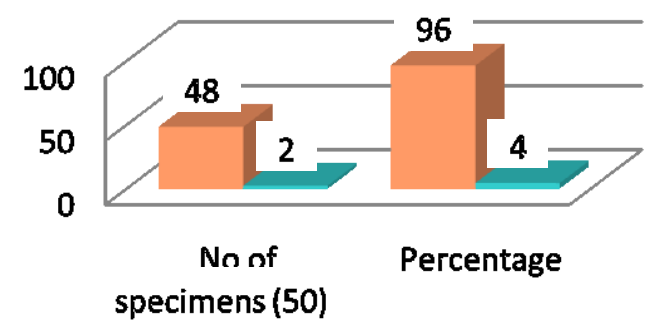

Extı hepatically Inti hepatically

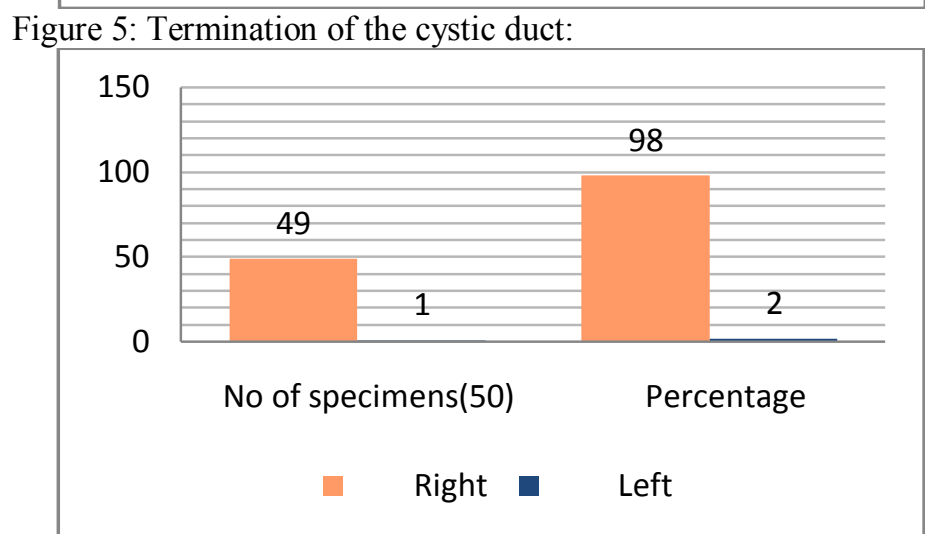

Figure 6: Incidence of the accessory hepatic duct.

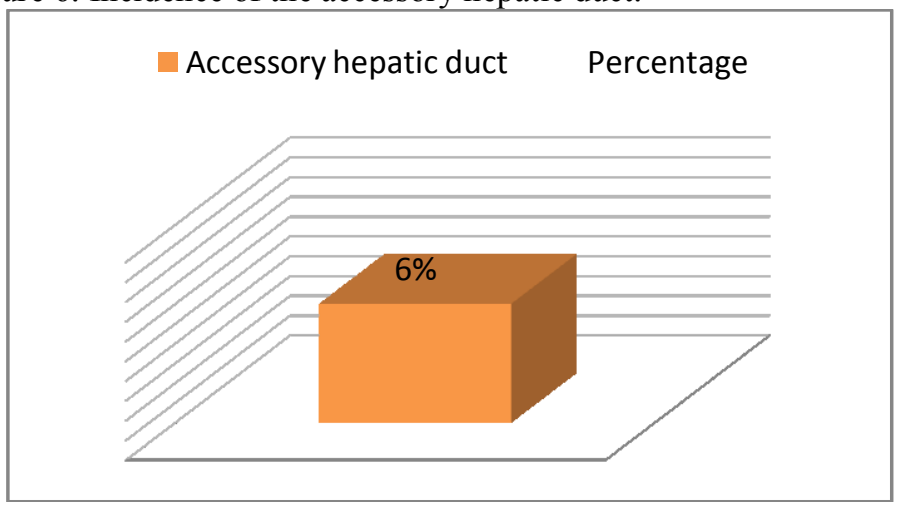

V. Discussion:

Thorough knowledge of anatomical variations in hepato-biliary system is important during surgical and endoscopic procedures as misinterpretation of normal anatomy and anatomical variations contribute to the occurrence of major postoperative complications like biliary injuries. This may occur following a cholecystectomy, the incidence being higher with laparoscopic cholecystectomy.

Bile is secreted by hepatocytes into the biliary canaliculi, which drains into the biliary ductules. The latter unite to form segmental bile ducts, which contribute to the formation of the right and left hepatic ducts at the level of porta hepatis. In $95 \%$ of cases, the left and right hepatic ducts join outside the liver, just below the porta hepatis, to form the common hepatic duct. In $5 \%$ of cases, they join inside the liver [2]. Intrahepatic union was also mentioned by Olsha $\mathrm{O}$ et al [3] and Vasitha Abeysuriya et al [4]. In the present study 4\% of cases had intrahepatic union.

The cystic duct joins the gallbladder to the bile duct and is one of the important structure needing proper identification and division during a standard cholecystectomy. The cystic duct may run a straight or a fairly convoluted course. True absence of the cystic duct is extremely rare and if the duct is not seen it is more likely to be hidden. The cystic duct joins the gallbladder at the neck and this angle may be fairly acute. Also the mode of joining may be smooth tapering or abrupt. On the bile duct side its mode of union shows significant variations. It is important to remember that even in the low insertion variety the cystic duct rarely goes behind duodenum and therefore a ductal structure passing behind the duodenum is more likely to be the bile duct itself [5]. Incidence of the cystic duct termination into common bile duct is as follows: Entry on the right side $17 \%$, 
Spiral duct with entry into posterior wall $41 \%$, Spiral duct with entry on the left $35 \%$ and parallel run with low insertion 7\% [5]. Abnormal termination of the cystic duct can occur in right and left hepatic ducts [6], rarely does the cystic duct insert into the duodenum from the gallbladder without forming common bile duct [4]. In this study, we found that in one specimen (2\%) the cystic duct opened into the left side of the common bile duct. Such variations constitute one of the major causes of bile duct injuries after laparoscopic cholecystectomy. In patients with drainage of the cystic duct into the left side of the common hepatic duct, it is generally preferable to leave a long cystic duct remnant instead of dissecting the cystic duct up to the left side of the common hepatic duct [7]. So it is extremely important to have adequate knowledge of such variations before the actual procedure is performed.

Accessory hepatic duct develops due to delayed division of the hepatic antrum into cystic and hepatic diverticula [8], otherwise persistence of the foetal connection between the liver and gallbladder [9]. Incidence of the accessory hepatic duct was $2.8 \%$, which arose from the right lobe of the liver and entered into the cystic duct [10]. Even it can enter the superior surface of the gallbladder or cystic duct $[11,12]$.The incidence of the accessory hepatic duct has been reported by different authors. Daseler et al found $1.6 \%$ of accessory hepatic duct in 500 specimens [12]. A cadaveric study by Flint [13] mentioned that the total incidence was $14.5 \%$ in 200 specimens. Among the Indian studies, Sharmila et al [14] studied on the South Indian population, the incidence being $15 \%$ in 40 specimens. Bharath et al [15] revealed $26.7 \%$ out of 30 specimens in North Indian population. Accessory hepatic duct arising from the right lobe of the liver is 9 times more common than that from left lobe of the liver [15]. According to Flint [13] termination of the accessory hepatic duct was classified into 3 types: Type 1 - termination in the upper half of common hepatic duct (or) in the right hepatic duct; Type 2 - termination in the lower half of common hepatic duct; Type 3 -termination at the union of cystic duct and common hepatic duct. In our study carried out on South Indian population (Chidambaram region, Tamilnadu) the total incidence was found to be $6 \%$. In all cases it arose from the right lobe of the liver and drained into neck of the gallbladder. Variations in the biliary tree may be or may not be related with hepatic arterial variants $[16,17]$. In the present study variation in the hepatic artery was not found.

\section{Conclusion:}

The anatomy of the extra-hepatic biliary apparatus is highly variable and some of these variations and anomalies can be problematic for surgeons during surgical procedures such as laparoscopic cholecystectomy, liver resection and living donor transplantation. Surgery carried out in ignorance of anomalies can result in major complications such as leakage of ducts or atrophy of liver. Therefore, it is important to have a thorough knowledge in successful detection and recognition of such anatomic variations thereby decreasing morbidity and mortality rates during hepatobiliary surgery.

\section{References:}

[1]. Romanes G.J. The abdomen. Thorax and abdomen,Cunningham's Manual Of Practical Anatomy.15 ${ }^{\text {th }}$ Edition. Volume 2. Oxford Madical Publications,2003:83-163.

[2]. Pellegrini CA and Duh Q-Y. Gallbladder and biliary tree: anatomy and structural anomalies. Textbook of gastroenterology. J.B. Lippincott Company, Philadelphia, Yamada T (ed),1991:1952-1966.

[3]. Olsha O, Steine A, Rivkin LA, Sheinfeld A. Congenital absence of the anatomica bile duct. Acta Chir Scand.1987;153:387 90[PubMed]

[4]. Vasitha Abeysuriya, Sujatha Salgado, Kemal 1 Deen, Sumudu K Kumarage. Hepaticocystic duct and a rare extra hepatic "cruciate" arterial anastomosis-A case report. Journal Of Medical Case Reports.2008;2:37. Doi. 1001186/1752-1947-237.[PMCID:PMC2262902]

[5]. George R.A, Debnath J, Singh K, Satija L, Bhargava S, Vaidya A. Low insertion of a cystic duct into the common bile duct as a cause for a malpositioned biliary stent: demonstration with multidirector computed tomography. Singapore Med J.2009;50(7):e24.

[6]. Alfred Cuschieri. Laparoscopic cholecystectomy. J.R.Coll.Surg.Edinb.1999;44:187-92.

[7]. Lamah M, Karanjia ND, Dickson GH. Anatomical Variations Of The Extrahepatic Biliary Tree: Review Of The World Literature. Clin Anat.2001;14:167-172.

[8]. Bismuth H, Nakche R. And Dimond T. Management Strategies In Resection For Hilar Cholangiocarcinoma. Annals Of Surgery.1992;215(1):31-32.

[9]. Walia HS, Abraham TK, Baraka. A Gallbladder Interposition:A Rare Anomaly Of The Extra Hepatic Ducts.Int Surg.1986;71:117 21[ PubMed ]

[10]. Klotz HP, Schlumpf R and Largiader F. Injury To An Accessory Bile Duct During Laproscopic Cholecystectomy. Surg Laparosc Endosc.1992;2:317-20. E.

[11]. Lurje A. The Topography Of The Extra Hepatic Biliary Passages. Ann. Surg. 1937;105:161 - 168.

[12]. HelouryY, Leborgne J, Rogez JM, Robert R, Lehur PA, Pannier M, Barbin JY. Radiological Anatomy Of The Bile Ducts Based On Intraoperative Investigation In 250 Cases. Anat Clin. 1985;7(2):93 -102.

[13]. Daseler EH, Barry, Anson BJ. The Cystic Artery And Constituents Of The Hepatic Pedicle. Surg. Gyne. Obst.1947;85: 47-63.

[14]. Flint E.R. Abnormalities In Anatomy Of Bile Tract. British J Surg.1922-23;10:509-519.

[15]. Sharmila A, Sumathilatha S, Chistilda Felicia Jebakani. Anatomical Variation In The Extra Hepatic Biliary Ductal System. Journal of Anatomical Society Of India.2011,60(1):50-52.

[16]. Bharath N.V., Srinivasa Rao Y., ThirupathinRao V., Kanhan M., BalajinP. Accessory Hepatic Duct . Journal Of Anatomical Society Of India.2010;59(1):48-139. 
Variations Of The Extrahepatic Biliary Tract: Cadaveric Study.

[17]. LeeV.S., Morgan G.R. and Lin J.C. Liver Transplant Donor Candidates: Association Between Vascular And Biliary Anatomic Variants. Liver Transplantation.2004;10(8):1049-1054.

[18]. Macdonald D.B, Haider M.A., Khalili K. Relationship Between Vascular And Biliary Anatomy In Living Liver Donors. American Journal of Roentgenology.2005;185(1):247-252. 